\title{
Fine-needle aspiration cytology of Warthin-like mucoepidermoid carcinoma: A case report with cytological review
}

\author{
YURI NODA $^{1}$, MITSUAKI ISHIDA ${ }^{1}$, KIMIAKI OKANO $^{1}$, KAORI SANDOH $^{1}$, YUSUKE EBISU $^{1}$, \\ CHIKA MIYASAKA $^{1}$, TAKUO FUJISAWA ${ }^{2}$, MASAO YAGI ${ }^{2}$, HIROSHI IWAI ${ }^{2}$ and KOJI TSUTA ${ }^{1}$ \\ Departments of ${ }^{1}$ Pathology and Laboratory Medicine and ${ }^{2}$ Otolaryngology, \\ Kansai Medical University, Hirakata, Osaka 573-1010, Japan
}

Received March 4, 2021; Accepted October 21, 2021

DOI: $10.3892 / \mathrm{mco} .2021 .2438$

\begin{abstract}
Warthin-like mucoepidermoid carcinoma (MEC) is a novel and rare subtype of MEC and is characterized histopathologically by the presence of abundant lymphocytic infiltration and cystic changes. A small number of cytological reports of this MEC variant is currently available. The present study reported on the sixth cytological case of Warthin-like MEC, reviewed the cytological features of the tumour and discussed the cytological differential diagnosis. A 16-year-old Japanese female presented with a painful mass in the left parotid gland. Fine-needle aspiration for cytological examination of the parotid gland tumour was performed, followed by partial parotidectomy. Cytological examination revealed sheet-like and folded epithelial cell clusters in a mucinous background accompanying abundant lymphocytic infiltration. Epithelial clusters comprised round cells with mildly enlarged round to oval nuclei, polygonal cells with relatively rich cytoplasm and slightly enlarged round to oval nuclei. Certain polygonal cells contained intracytoplasmic mucin. Histopathological examination of the resected parotid gland tumour indicated multiple cystic lesions with abundant lymphocytic infiltration accompanying lymphoid follicle formation. The cysts were lined by intermediate cells with occasional mucinous cells. Fluorescence in situ hybridization using the surgically resected specimen indicated mastermind-like transcriptional coactivator 2 (MAML2) rearrangement, a characteristic of Warthin-like MEC. Consequently, the patient was diagnosed with Warthin-like MEC. The literature review revealed that the characteristic cytological features of Warthin-like MEC are the presence of intermediate cells and lack of oncocytic cells in the mucinous material under an abundant lymphocytic
\end{abstract}

Correspondence to: Dr Mitsuaki Ishida, Department of Pathology and Laboratory Medicine, Kansai Medical University, 2-5-1 Shinmachi, Hirakata, Osaka 573-1010, Japan

E-mail: ishidamt@hirakata.kmu.ac.jp

Key words: Warthin-like mucoepidermoid carcinoma, mucoepidermoid carcinoma, parotid gland, fine-needle aspiration, cytology background. Clinicopathological features may help with a differential diagnosis, particularly from Warthin's tumour, and detection of MAML2 rearrangement is able to improve the accuracy of diagnosis.

\section{Introduction}

Mucoepidermoid carcinoma (MEC) is the most common malignancy originating in the salivary gland $(1,2)$ and Warthin-like MEC was recently categorized as a novel and low-grade form of this disease (3). This rare variant is characterized histopathologically by the presence of prominent lymphocytic infiltration and cystic changes that resemble Warthin's tumour (3). The neoplastic cells comprising Warthin-like MEC are intermediate cells and a variable number of mucinous cells may be present, similar to that in conventional MEC; however, the bi-layered tall oncocytic cells, which are characteristic of Warthin's tumour, are not observed in Warthin-like MEC $(3,4)$. Mastermind-like transcriptional coactivator 2 (MAML2) encodes a transcription coactivator of NOTCH proteins. The presence of MAML2 rearrangement is characteristic of Warthin-like MEC (3). This rearrangement is observed in most cases of conventional MEC, particularly in low-grade tumours (3).

Fine-needle aspiration (FNA) cytology is a useful technique for diagnosing salivary gland tumours (5-7). However, the cytological features of Warthin-like MEC have remained to be fully established due to its rarity (8-11). In the present study, the sixth cytological case of Warthin-like MEC was reported, which occurred in a 16-year-old Japanese female. The clinicopathological and cytological features of the present and previously reported Warthin-like MEC cases were also reviewed and the considerations for cytological differential diagnosis were discussed.

\section{Case report}

A 16-year-old Japanese female visited Kansai Medical University (Hirakata, Japan) with a painful mass on the left side of the neck in April 2020. The patient had no notable medical or family history. Physical examination revealed a relatively well-circumscribed and mobile tumour in the left parotid gland; no facial nerve palsy was noted. Magnetic 


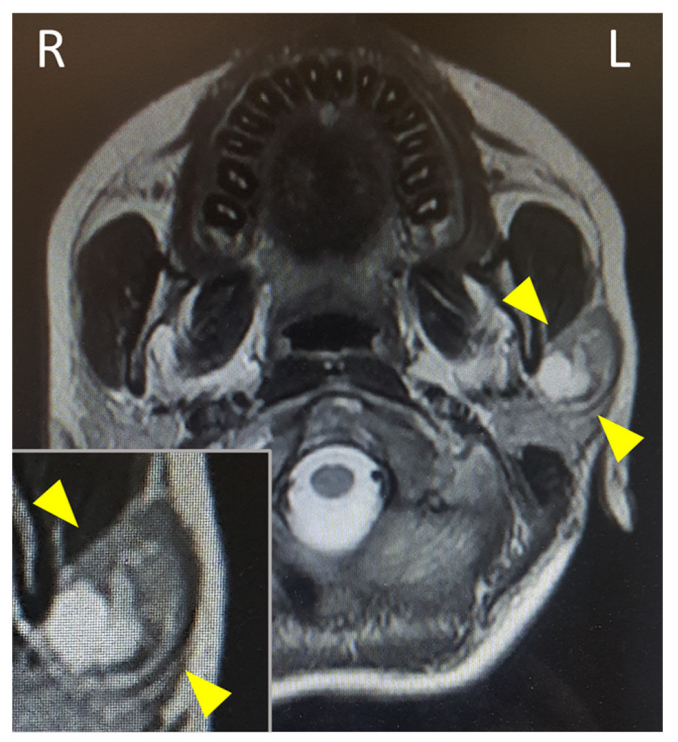

Figure 1. Magnetic resonance imaging reveals a well-circumscribed tumorous lesion with multiple cysts and solid components in the left parotid gland. The magnified window displays the lesion (arrowheads).

resonance imaging revealed a well-circumscribed tumour accompanying multiple cysts and solid masses with intermediate intensity in the left parotid gland (Fig. 1, inset). FNA examination of the left parotid gland tumour was performed and the specimens were stained by Papanicolaou stain as the same method previously reported $(6,10)$. The results of FNA examination were available prior to surgery. No cell block method was applied in the present case, as this method is not routinely performed at our hospital. Considering the presence of the painful mass in the parotid gland, partial parotidectomy was performed, without any specific clinical diagnosis, as the initial FNA results were negative for cancer. Intraoperative findings revealed a relatively well-circumscribed mass in the left parotid gland and the mass was not in contact with the facial nerve. The facial nerve activity was monitored using an electromyography monitor during the operation. After six months of post-surgery follow-up and without any additional therapy, the patient has presented no evidence of recurrence. This patient was subjected to standard clinical treatment, as Warthin-like MEC is considered a low-grade malignancy $(1,3)$.

\section{Results}

Initial cytological features of the parotid gland tumour. The Papanicolaou smear of the FNA specimens revealed the presence of sheet-like, folded or scattered epithelial cell clusters and a small number of non-neoplastic acinar cells in a mucinous background accompanying abundant lymphocytes and scattered macrophages (Fig. 2A). The epithelial cell clusters comprised round cells with mildly enlarged round to oval nuclei without nucleoli (Fig. 2B) and polygonal cells with relatively rich cytoplasm and slightly enlarged round to oval nuclei accompanying small nucleoli (Fig. 2B and C). Certain polygonal cells had intracytoplasmic mucin, eccentric nuclei and lace-like cytoplasm (Fig. 2C). No necrotic material, keratinized cells or oncocytes were observed. Accordingly, an initial cytological diagnosis of lymphoepithelial sialadenitis (LS) was made.

Histopathology of parotid gland tumour. Macroscopic examination of the resected tumour revealed a well-circumscribed tumour that was white to pale yellow in colour (Fig. 3A). Histopathological examination indicated multiple variable-sized cysts with abundant lymphocytic infiltration accompanying lymphoid follicle formation around the cysts (Fig. 3B). These cysts were lined by intermediate cells with mildly enlarged round to oval nuclei without conspicuous nucleoli, with interspersed mucinous cells (Fig. 3C). No keratinization or bi-layered oncocytes were noted. Fluorescence in situ hybridization using the surgically resected specimen detected MAML2 rearrangement (Fig. 3D). Accordingly, a diagnosis of Warthin-like MEC was made. The presence of intermediate cells and mucinous cells, in addition to the abundant lymphocytic infiltration in the histopathological specimen, corresponded to the observations in the cytological specimen.

\section{Discussion}

The present study reported the sixth cytological Warthin-like MEC case. To the best of our knowledge, only 22 cases, including the present case, have been reported since the first report by Ishibashi et al (3) in 2015 (8-15). Table I summarizes the clinicopathological features of Warthin-like MEC. The most common and chief complaint is a painless mass. All cases occur in the parotid gland and females are preferentially affected (females/males, 18:4). This type of tumour commonly appears in middle-aged individuals (mean age, 44 years); however, it may also occur in teenagers and four cases, including the present one, have been reported, while the total age range is $13-60$ years. There were no obvious regional or nationality preferences. These clinical characteristics are similar to those of conventional MEC, which is more likely to occur in females and may affect the paediatric population $(1,15)$. Radiological features were available for nine cases: Ultrasonography $(9,11)$ and computed tomography $(8,10,15)$ revealed a well-circumscribed tumour with multiple cysts. Magnetic resonance imaging displayed a low- or intermediate-intensity tumour $(10-12,15)$. These features are consistent with those of conventional low-grade MEC (16).

Cytological features of Warthin-like MEC have been reported for six cases (8-11), including the present case, although MAML2 rearrangement was not evaluated in one case (9). Table II summarizes the cytological features of these cases. The characteristic cytological features are the presence of cystic contents, including a mucin and proteinaceous material background, and lymphocyte abundance. Squamous, intermediate and mucinous cells were observed in three, four and four cases, respectively. Nuclear atypia was mild in all cases. No oncocytic cells, as observed in most of the cytological Warthin's tumour specimens, were noted in the Warthin-like MEC cases. Only one case was initially cytodiagnosed as MEC (9), but none as Warthin-like MEC (Table II). FNA cytology frequently fails to obtain solid components in cases with conventional low-grade MEC (6), which mainly involves cystic components; therefore, it is predicted that obtaining solid components, such as squamous, 

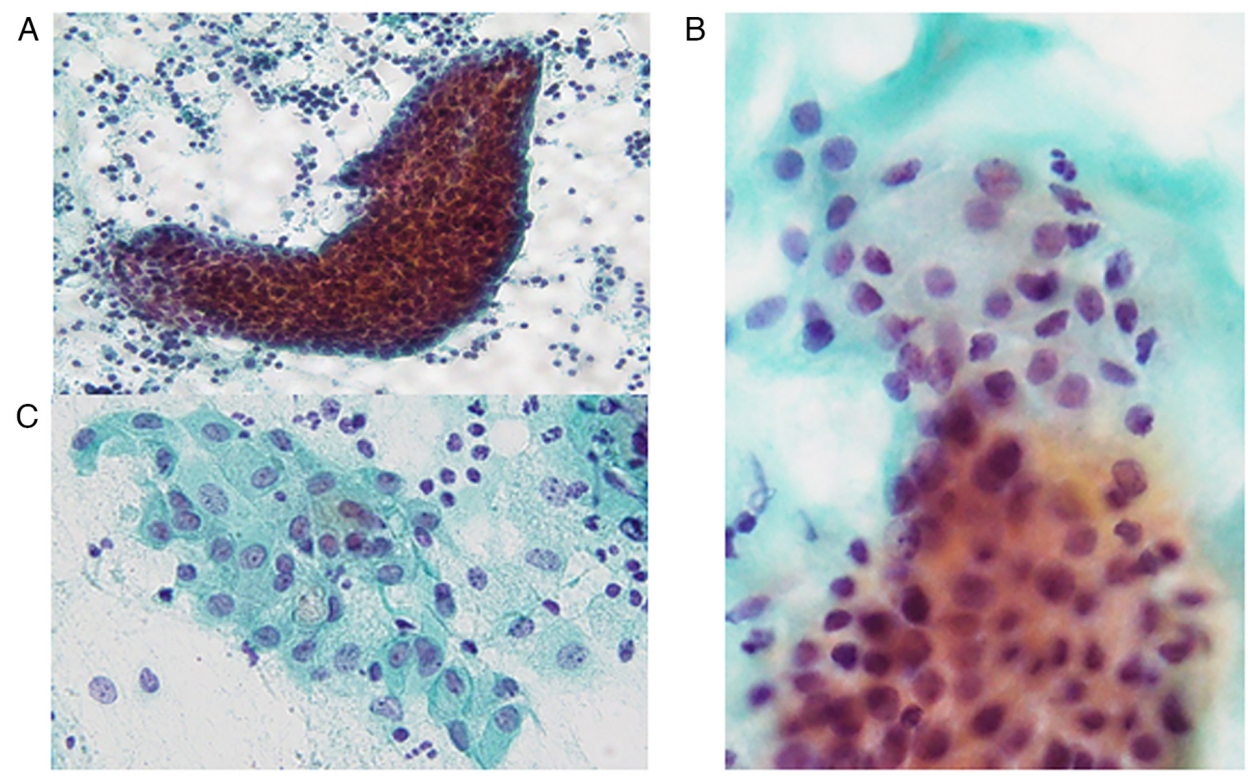

Figure 2. Cytological features of the parotid gland tumour biopsied by fine-needle aspiration. (A) Sheet-like and folded epithelial cell clusters in a mucinous background with abundant lymphocytes (Papanicolaou stain; magnification, x100). (B) Sheet-like epithelial cell cluster comprises round cells with slightly enlarged round to oval nuclei without nucleoli and polygonal cells with relatively rich cytoplasm and slightly enlarged round nuclei (Papanicolaou stain; magnification, x400). (C) Polygonal cells have relatively rich cytoplasm and mildly enlarged nuclei with a small nucleolus. Mucinous cells were also observed (Papanicolaou stain, magnification, $\mathrm{x} 400$ ).
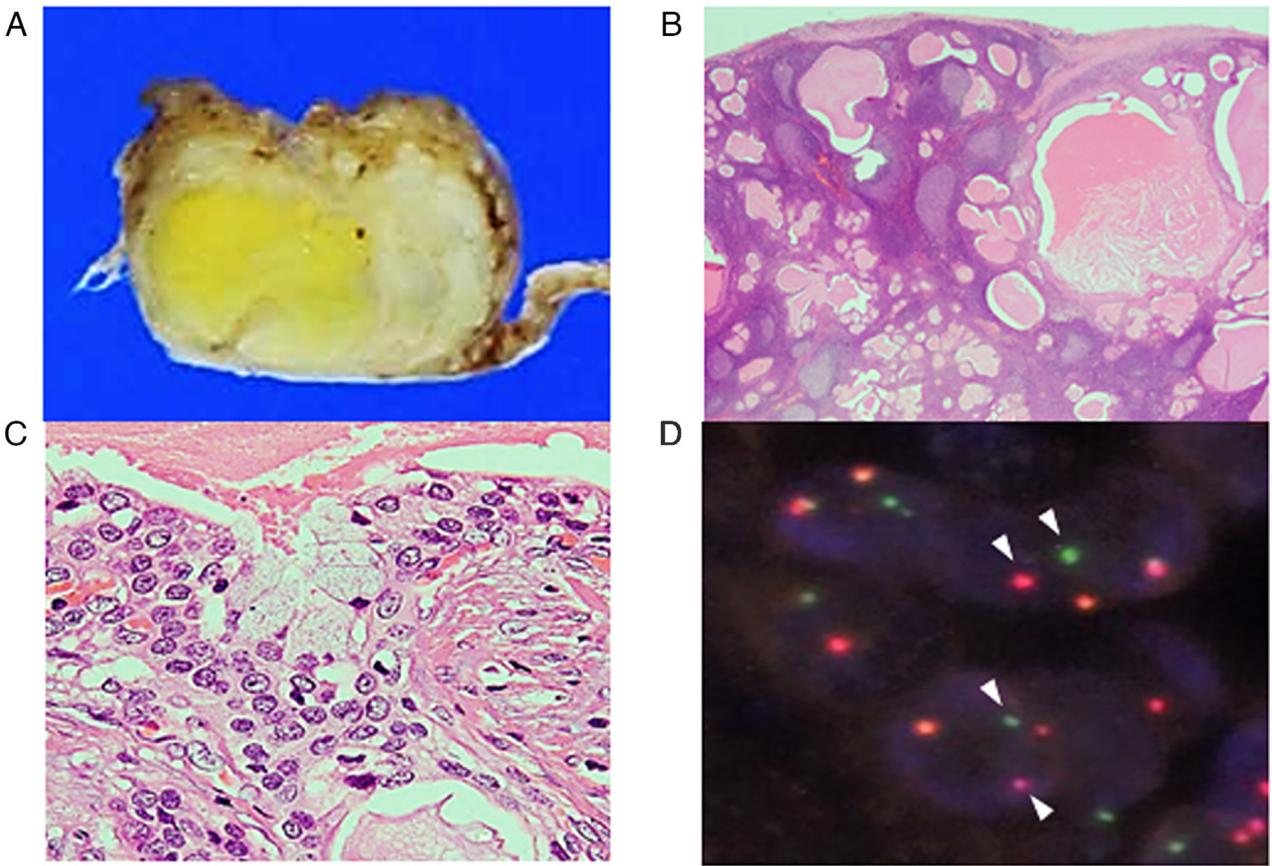

Figure 3. Histopathological features of the parotid gland tumour. (A) On macroscopic examination, the tumour was relatively well-circumscribed and white to pale yellow in colour. (B) On histology, multiple cysts accompanying abundant lymphocytic infiltration and lymphoid follicle formation were revealed; (C) cysts were lined by intermediate cells and occasional mucinous cells (haematoxylin and eosin; magnification, x400). (D) Break-apart fluorescence in situ hybridization for $M A M L 2$ rearrangement indicates split signals (arrowheads indicate non-altered signals; magnification, x1,000). MAML2, mastermind-like transcriptional coactivator 2 .

intermediate and mucinous cells, is difficult in Warthin-like MEC. In the cytological case series of Warthin-like MEC, only one case harboured the above-mentioned cells (Table II). These cytological features and the presence of lymphocyte abundance in a background with mild nuclear atypia make the cytological diagnosis of Warthin-like MEC difficult.
Cytological differential diagnoses of Warthin-like MEC includes Warthin's tumour and LS. The characteristic cytological features of Warthin's tumour include the combined presence of oncocytes with or without squamous/mucinous metaplastic cells and lymphocytes in the proteinaceous background (17). Intermediate cells are not observed in Warthin's tumour (17). 


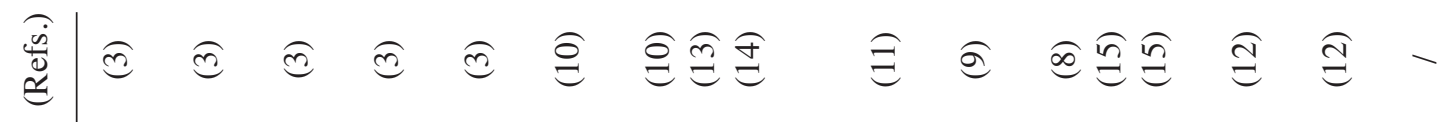

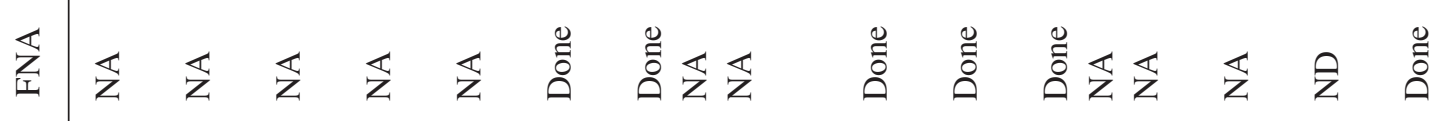

$\frac{\sqrt[n]{2}}{\sqrt[n]{2}}$

营

ż

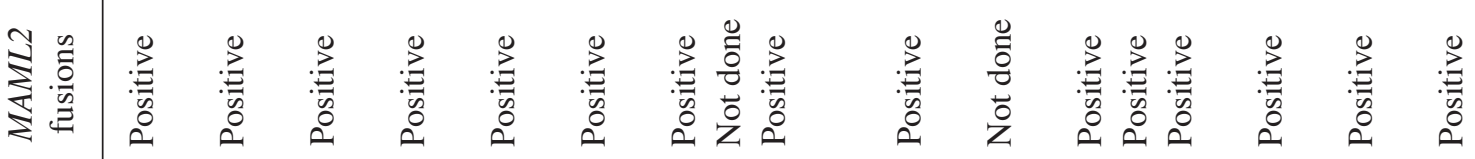

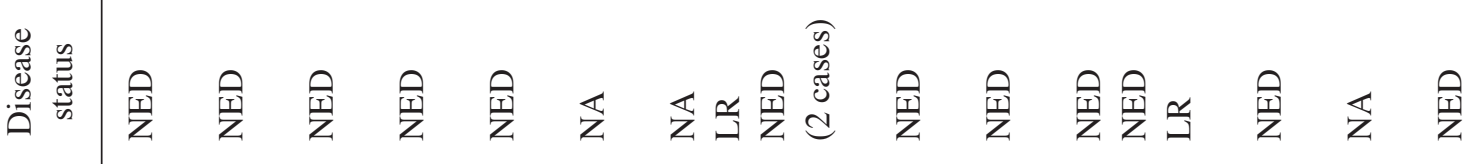

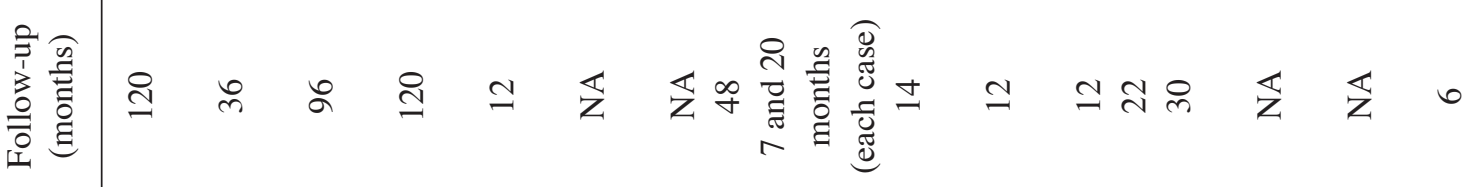

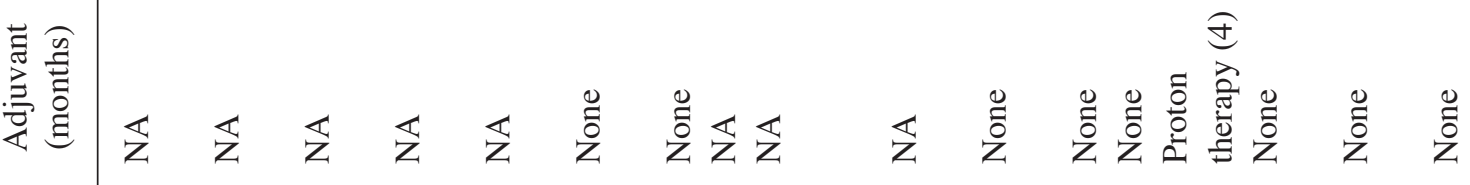

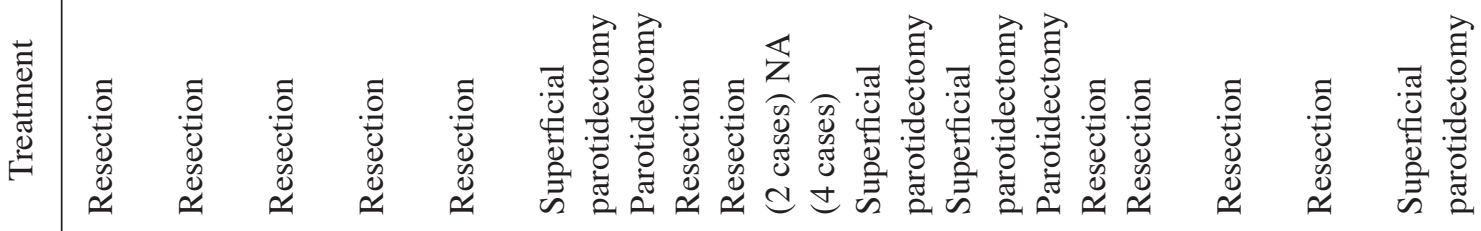

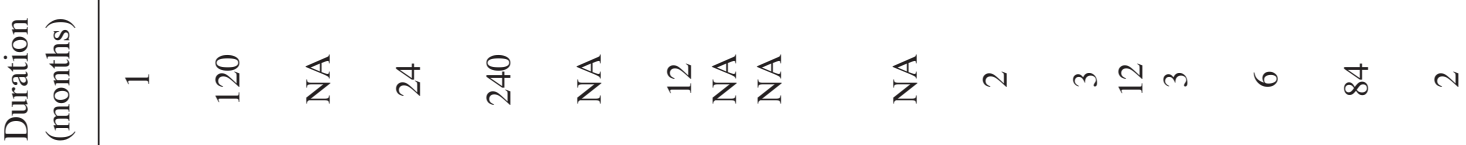

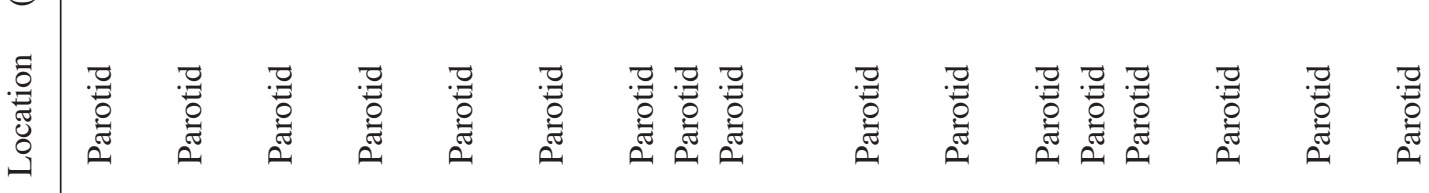

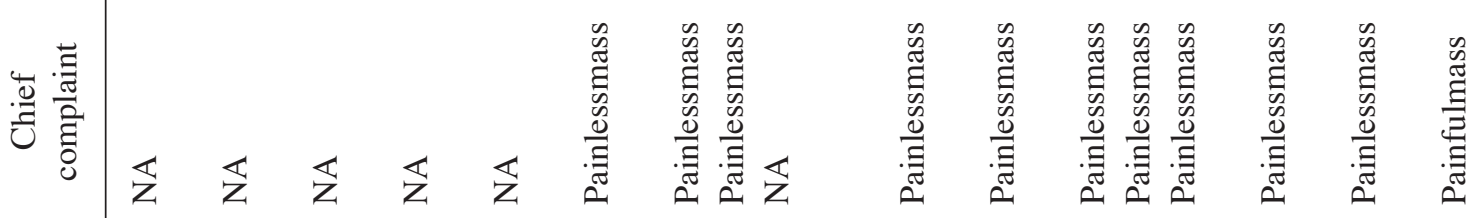

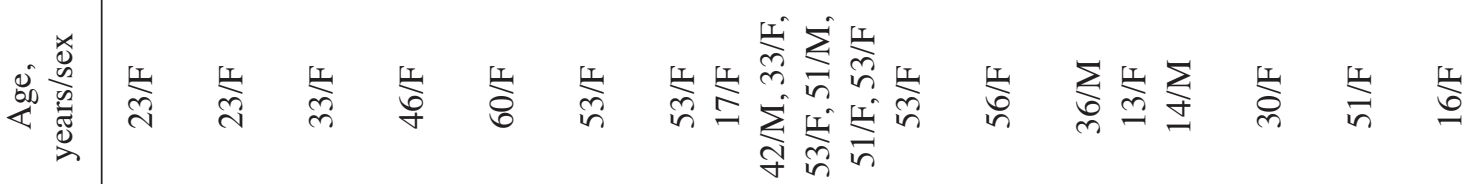

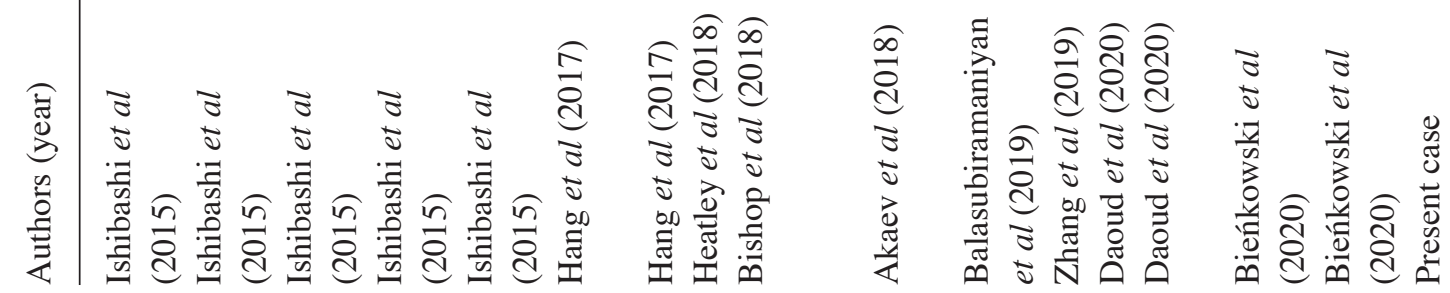




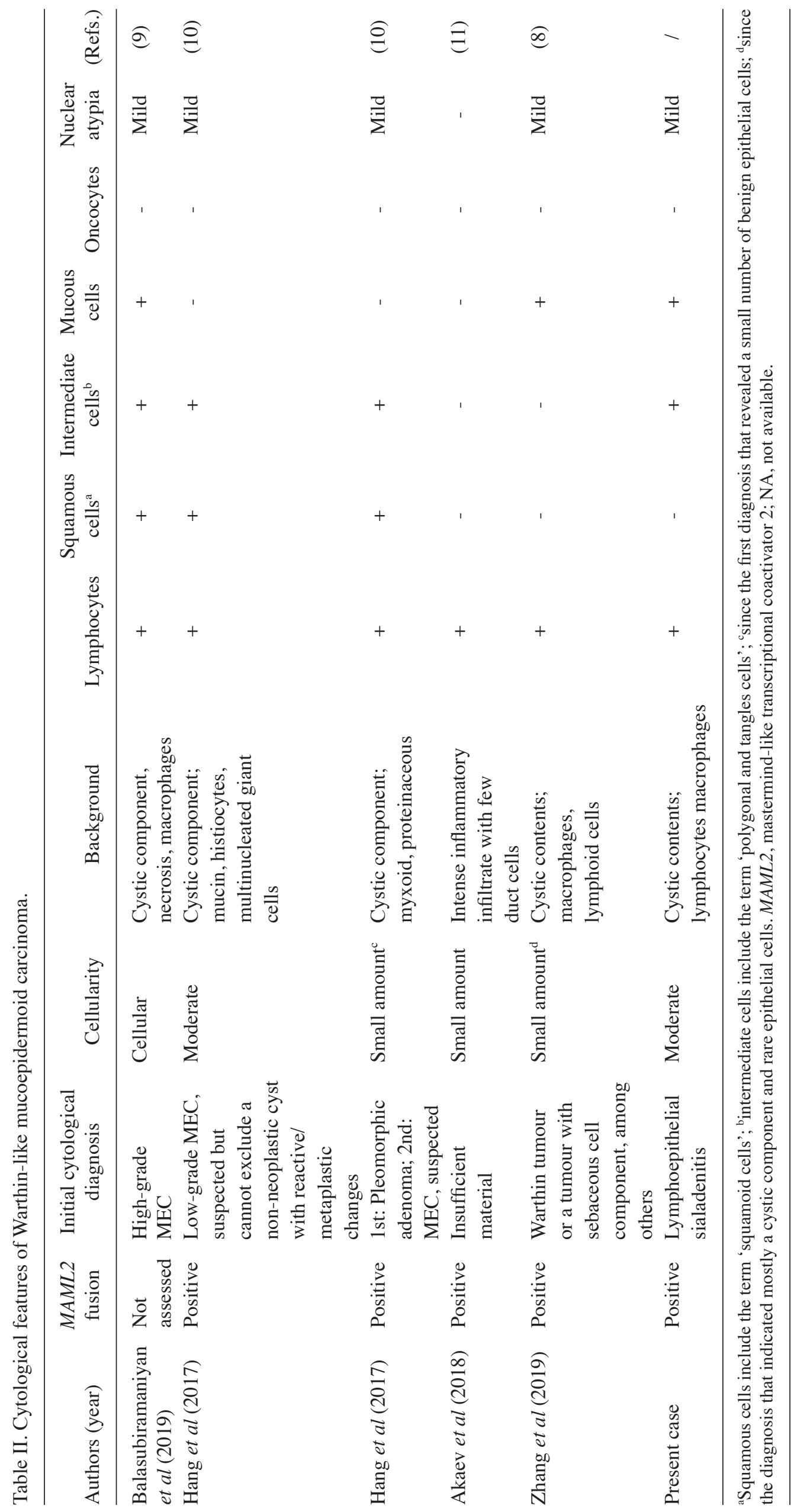


The clinicopathological features are useful for differential diagnosis, as Warthin's tumour frequently occurs in the bilateral parotid glands and mainly arises in 50- to 60-year-old males with a history of cigarette smoking $(1,2)$, which differs from that of Warthin-like MEC. Oncocytic metaplastic cells, as well as squamous and mucinous metaplastic cells, may be present in LS; however, intermediate cells and mucinous fluid have not been observed (18). In the present case, the presence of intermediate cells in the cytological specimens was overlooked (as intermediate cells exhibited mild nuclear atypia, mimicking the non-neoplastic cells, as described earlier), leading to the initial diagnosis of LS and not Warthin-like MEC. The presence of mucinous fluid and abundant lymphocytes in the background, intermediate cells and lack of oncocytic cells may be key cytological features of Warthin-like MEC, although a definitive cytological diagnosis may be difficult to reach and the correlation with clinicoradiological features is important.

The most critical diagnostic clue for Warthin-like MEC is MAML2 rearrangement (3), as observed in the present case. Cyclic adenosine monophosphate responsive element binding protein-regulated transcription coactivator 1/3-MAML2 fusions occur in $>50 \%$ of conventional MECs, which are specific to $\operatorname{MEC}(3,12,19)$ and are correlated with low-/intermediate-grade histology and improved prognosis $(17,20)$. Fluorescence in situ hybridization using cellblock specimens is used for detecting MAML2 rearrangement in conventional MEC diagnosis (20); however, no such analysis for Warthin-like MEC using cytological specimens has been described. Further studies are required to clarify the usefulness of gene rearrangement analysis using cytological specimens for the diagnosis of Warthin-like MEC diagnosis.

In conclusion, the present study described an additional cytological case of Warthin-like MEC and reviewed the cytological features of this rare tumor for the first time. The characteristic FNA cytological features of this rare tumour type are the presence of mucinous material and abundant lymphocytes in the background, the presence of intermediate cells and the lack of oncocytic cells. It is crucial for cytologists and cytopathologists to recognize these features. Clinicopathological characteristics may help with differential diagnoses, particularly from Warthin's tumour, and the detection of MAML2 rearrangement leads to an accurate diagnosis.

\section{Acknowledgements}

Not applicable.

\section{Funding}

No funding was received.

\section{Availability of data and materials}

All data generated or analysed during this study are included in this published article.

\section{Authors' contributions}

Conception and design of the study: YN and MI; data collection and analysis: YN, MI, KO, KS, YE, CM, TF, MY, HI and KT; confirmation of the authenticity of all raw data: YN and MI; drafting the manuscript and figures: YN and MI. All authors read and approved the final manuscript.

\section{Ethics approval and consent to participate}

This study was conducted in accordance with the Declaration of Helsinki and the study protocol was approved by the Institutional Review Board of Kansai Medical University Hospital (approval no. 160646). Opt-out consent was obtained from the participant of this study.

\section{Patient consent for publication}

Opt-out consent was obtained from the participant of this study.

\section{Competing interests}

The authors declare that they have no competing interests.

\section{References}

1. El-Naggar AK and JKC C: World Health Organization Classification of Head and Neck Tumours. 4th edition. Grandis JR, Takata T, Grandis J and Slootweg P (eds). IARC, Lyon, 2017.

2. AFIP Atlas of Tumor Pathology, 4th Series Fascicle: Tumors of the Salivary Glands. Ellis GL, Auclair PL (eds). ARP, Arlington, 2007.

3. Ishibashi K, Ito Y, Masaki A, Fujii K, Beppu S, Sakakibara T, Takino H, Takase H, Ijichi K, Shimozato K and Inagaki H: Warthin-like mucoepidermoid carcinoma: A combined study of fluorescence in situ hybridization and whole-slide imaging. Am J Surg Pathol 39: 1479-1487, 2015.

4. Zhang X, Baloch ZW, Cooper K, Zhang PJ, Puthiyaveettil R and LiVolsi VA: The significance of mucinous metaplasia in Warthin tumor: A frequent occurrence and potential pitfall. Hum Pathol 99: 13-26, 2020.

5. Sandhu VK, Sharma U, Singh N and Puri A: Cytological spectrum of salivary gland lesions and their correlation with epidemiological parameters. J Oral Maxillofac Pathol 21: 203-210, 2017.

6. Joseph TP, Joseph CP, Jayalakshmy PS and Poothiode U: Diagnostic challenges in cytology of mucoepidermoid carcinoma: Report of 6 cases with histopathological correlation. J Cytol 32: 21-24, 2015.

7. Al-Khafaji BM, Nestok BR and Katz RL: Fine-needle aspiration of 154 parotid masses with histologic correlation: Ten-year experience at the University of Texas M.D. Anderson Cancer Center. Cancer 84: 153-159, 1998

8. Zhang D, Liao X, Tang Y, Meyer RG, Van Dyke DL, Liu X, Islam MN and Lai J: Warthin-like mucoepidermoid carcinoma of the parotid gland: Unusual morphology and diagnostic pitfalls. Anticancer Res 39: 3213-3217, 2019.

9. Balasubiramaniyan V, Sultania M, Sable M, Muduly D and Kar M: Warthin-like mucoepidermoid carcinoma of the parotid gland: A diagnostic and therapeutic dilemma. Autops Case Rep 9: e2019122, 2019.

10. Hang JF, Shum CH, Ali SZ and Bishop JA: Cytological features of the Warthin-like variant of salivary mucoepidermoid carcinoma. Diagn Cytopathol 45: 1132-1136, 2017.

11. Akaev I, Yeoh CC, Brennan PA and Rahimi S: Low grade parotid mucoepidermoid carcinoma with tumour associated lymphoid proliferation ('Warthin-like') and CRTC1-MAML2 fusion transcript: Definitive diagnosis with molecular investigation only. Oral Oncol 80: 98-99, 2018.

12. Bieńkowski M, Kunc M, Iliszko M, Kuźniacka A, Studniarek M and Biernat W: MAML2 rearrangement as a useful diagnostic marker discriminating between Warthin tumour and Warthin-like mucoepidermoid carcinoma. Virchows Arch 477: 393-400, 2020.

13. Heatley N, Harrington KJ and Thway K: Warthin tumor-like mucoepidermoid carcinoma. Int J Surg Pathol 26: 31-33, 2018. 
14. Bishop JA, Cowan ML, Shum $\mathrm{CH}$ and Westra WH: MAML2 rearrangements in variant forms of mucoepidermoid carcinoma: Ancillary diagnostic testing for the ciliated and Warthin-like variants. Am J Surg Pathol 42: 130-136, 2018.

15. Daoud EV, McLean-Holden AC, Pfeifer CM, Timmons CF Oliai BR and Bishop JA: Pediatric Warthin-like mucoepidermoid carcinoma: Report of two cases with one persistent/recurrent as conventional mucoepidermoid carcinoma. Head Neck Pathol 14 923-928, 2020

16. Wang YQ, Mo YX, Li S, Luo RZ, Mao SY and Shen JX: Low-grade and high-grade mucoepidermoid carcinoma of the lung: CT findings and clinical features of 17 cases. AJR Am J Roentgenol 205: 1160-1166, 2015

17. Flezar M and Pogacnik A: Warthin's tumour: Unusual vs. common morphological findings in fine needle aspiration biopsies. Cytopathology 13: 232-241, 2002.
18. Ronchi A, Montella M, Marra PM, Colella G, Franco R and Cozzolino I: Myoepithelial sialadenitis with metachromatic matrix: A diagnostic pitfall. A case of salivary gland swelling in a paediatric patient evaluated by fine needle aspiration cytology. Cytopathology 32: 257-260, 2021.

19. Nakayama T, Miyabe S, Okabe M, Sakuma H, Ijichi K, Hasegawa Y, Nagatsuka H, Shimozato K and Inagaki H: Clinicopathological significance of the CRTC3-MAML2 fusion transcript in mucoepidermoid carcinoma. Mod Pathol 22: 1575-1581, 2009

20. Darras N, Mooney KL and Long SR: Diagnostic utility of fluorescence in situ hybridization testing on cytology cell blocks for the definitive classification of salivary gland neoplasms. J Am Soc Cytopathol 8: 157-164, 2019.

c) (i) () $($ This work is licensed under a Creative Commons Attribution-NonCommercial-NoDerivatives 4.0 International (CC BY-NC-ND 4.0) License. 